\title{
Outcome of health-related legal challenges is sometimes surprising
}

Published at www.cmaj.ca on Oct. 9

$\mathrm{A}$ $\mathrm{n}$ analysis of health carerelated legal challenges based on the Canadian Charter of Rights and Freedoms indicates that even failed bids can yield beneficial outcomes, while successful bids have not always been enforced, a health law expert says.

As a consequence, people considering legal action should ask themselves if litigation "will help or hurt their cause," Colleen Flood, scientific director of the Canadian Institutes of Health Research's Institute of Health Services and Policy Research, told the 2009 National Health Law Conference in Montréal, Quebec, on Oct. 3.

Flood examined the outcomes of 46 Charter challenges in the areas of right to therapy, timely access to care, hospital restructuring and provider and consumer rights. Of those, 17 were successful and 29 failed.

Some of the successful cases were ultimately underenforced, while some of the unsuccessful challenges led to policy changes that favoured litigants, said Flood, who holds a Canada Research Chair in health law and policy at the University of Toronto in Ontario.

For example, in the only successful right-to-therapy challenge, the Supreme Court of Canada agreed that medical sign language interpreters should be available in hospitals (Eldridge v. British Columbia [Attorney General], 1997; 3 SCR 624). However, only Ontario and British Columbia have followed through on the court order and access in those provinces is limited. In BC, those who need the service face waits of more than two weeks, while in Ontario, by 2006 , only two interpreters were available after hours for hospitals in Toronto, which is home to about 30 000 deaf people, Flood said.

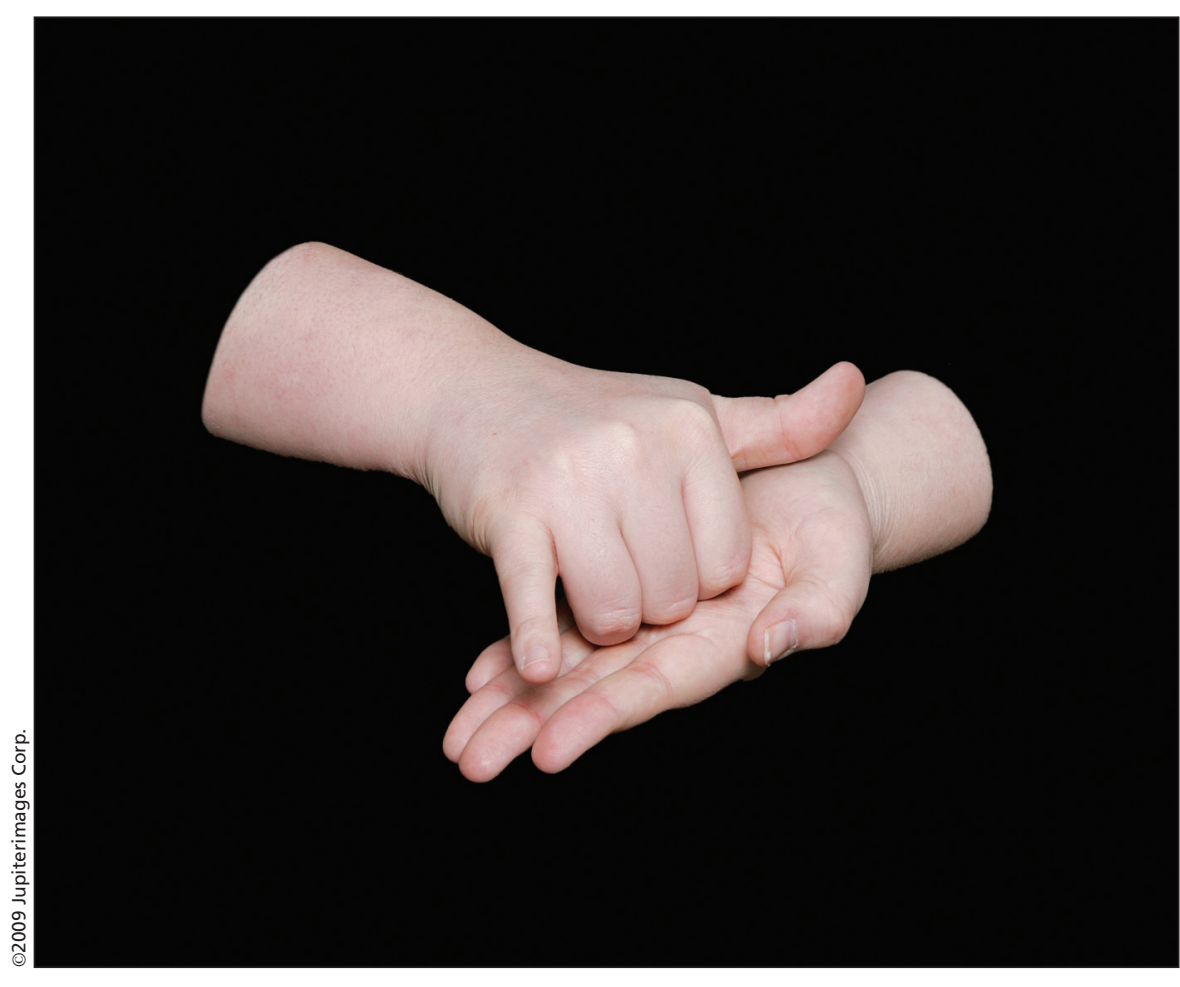

In the only successful right-to-therapy challenge in Canada, the Supreme Court of Canada ruled that sign language interpreters should be available in hospitals.

When the courts have removed prohibitions related to health care, governments need not actively ensure access, Flood said. For example, a 1988 Supreme Court of Canada ruling struck down the abortion provisions in the Criminal Code, which meant that approval by a therapeutic abortion committee was no longer necessary to qualify for a hospital abortion.

But access to hospital-provided therapeutic abortions dropped from $21 \%$ of hospitals in 1988 to $15.9 \%$ in 2006, Flood said.

The disbanded Canadian Abortion Rights Action League attributed the decline in access to hospital closings and the amalgamation of religious and secular hospitals, Flood added. "So you win and lose at the same time."

In other instances, Charter challenges failed but have resulted in posi- tive policy outcomes, Flood noted. In 2004, the Supreme Court of Canada ruled that governments have no obligation to fund "intensive behaviour intervention therapy" for autism but by the end of 2006 all jurisdictions except Nunavut provided some amount of funding.

Conversely, a failed Charter challenge can stymie political action and policy initiatives, Flood said, citing a 1999 rulling in which the Nova Scotia Court of Appeal rejected a Charter argument that in vitro fertilization is medically necessary and should be eligible for public funding.

Canada is one of the few developed countries that does not provide publicly funded access to in vitro fertilization and the Nova Scotia ruling "is arguably a factor in Canada's outlier approach," Flood said. 
Flood also told the conference that the rise of health care human rights as embodied in the United Nations covenant on the right to health - has raised fears that an individualistic approach to rights could "undermine the collective health care system."

As well, Flood said aspects of the law that shore up the public health care system are increasingly being challenged. For example, the Supreme
Court of Canada ruling that Quebec's ban on private health insurance for medically necessary services violated provincial human rights law (Chaoulli and Zeliotis v. A.G. Quebec et al.), has "spawned litigation across the country."

"A lot of what we thought was illegal is now happening," Flood said, citing the example of relatively new private health care insurance offerings that are promoted as a way to bypass hospital waiting lists.

The use of court challenges in health care also begs the question of whether the law is being used "for improved access for the marginalized," Flood said. "Or is the law being used by the privileged in society?" - Ann Silversides, CMAJ

DOI:10.1503/cmaj.109-3075 